\title{
NORTHEAST FOREST FRAGMENTATION INFORMATION NETWORK VERSION 1.0: ANALYSIS OF RESOURCES AND GAPS
}

\section{Technical Report}
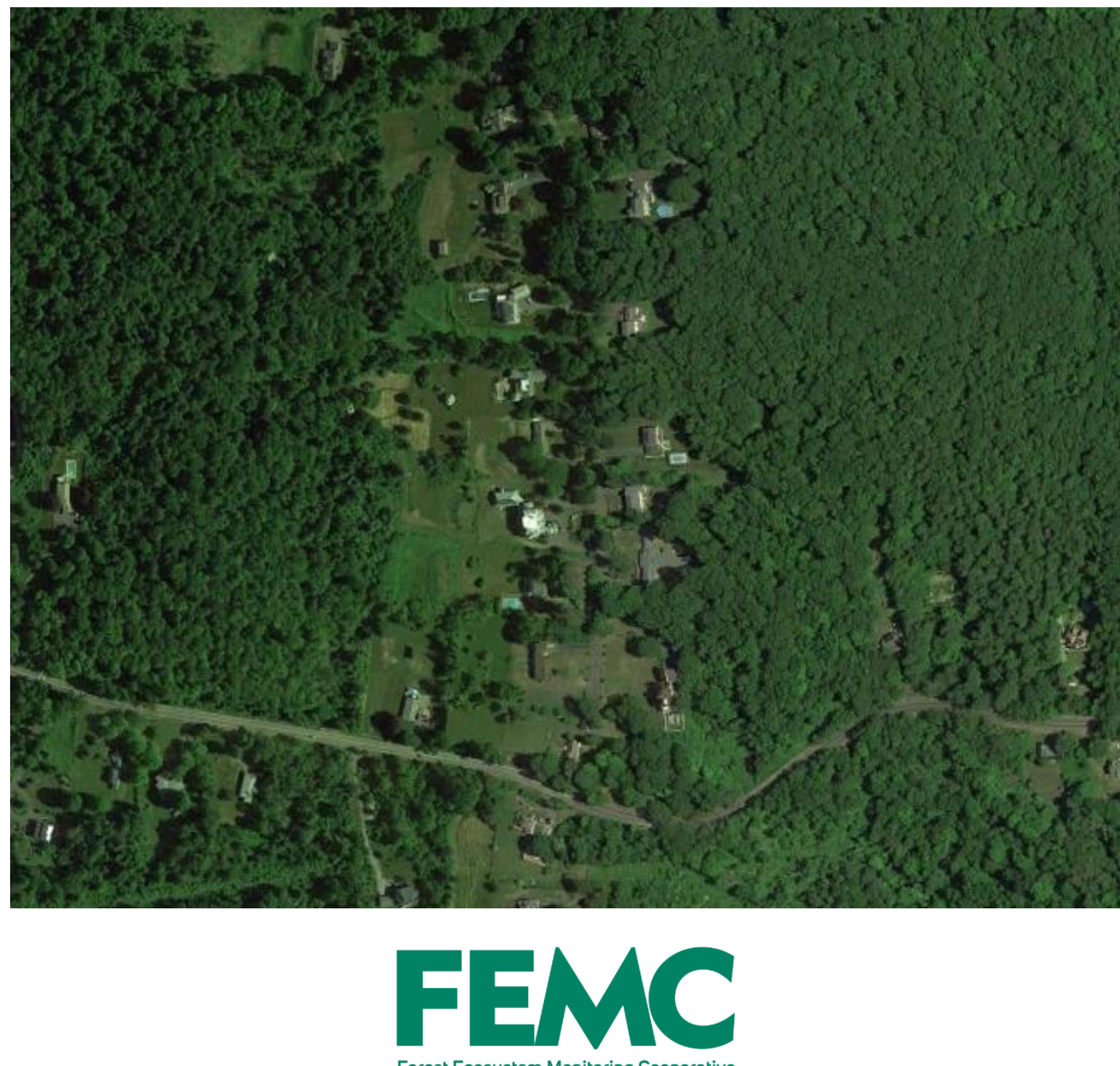

Forest Ecosystem Monitoring Cooperative

Last updated: September 23, 2019 


\section{Northeast Forest Fragmentation Information Network Version 1.0: Analysis of Resources and Gaps}

Published September 23, 2019

Version 1.0

Forest Ecosystem Monitoring Cooperative

South Burlington, VT, USA

femc@uvm.edu

(802) 656-2975

Alexandra Kosiba $^{a, b}$, John Truong ${ }^{a, b}$, James Duncan ${ }^{a, b}$, Mike Finnegan ${ }^{a, b}$, and Jennifer Pontius ${ }^{a, b, c}$.

a Forest Ecosystem Monitoring Cooperative, 705 Spear Street, South Burlington, VT, USA

b University of Vermont, Rubenstein School of Environment and Natural Resources, 81 Carrigan Drive, Burlington, VT, USA

${ }^{c}$ Forest Service, U.S. Department of Agriculture, Northern Research Station, Burlington, VT, USA

DOI: https://doi.org/10.18125/d1y18y

Cover image: Google ${ }^{\mathrm{TM}}$, Digital Globe

\section{Preferred Citation}

Kosiba, AM, Truong, J, Duncan JA, Finnegan MO, and Pontius, J. 2019. Northeast Forest Fragmentation Information Network Version 1.0: Analysis of Resources and Gaps. Forest Ecosystem Monitoring Cooperative: South Burlington, VT. https://doi.org/10.18125/d1y18y

Available online at https://www.uvm.edu/femc/fragnet/gap analysis

\section{Acknowledgements}

The Forest Ecosystem Monitoring Cooperative (FEMC) would like to acknowledge the contributions of the FEMC's committees in developing FragNet. A number of FEMC interns and staff worked to compile these resources, including Ismar Biberovic, Caroline Drayton, Mim Pendleton, Steve Rotella, and Emma Tait.

We are appreciative of the long-term funding from the U.S. Department of Agriculture, Forest Service State \& Private Forestry, Vermont Agency of Natural Resources and the University of Vermont that made this report possible.
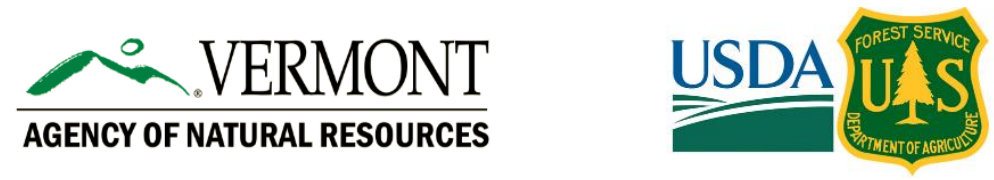

The UNIVERSITY of VERMONT 


\section{Table of Contents}

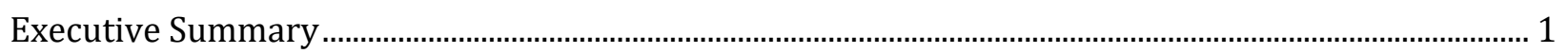

Methodology

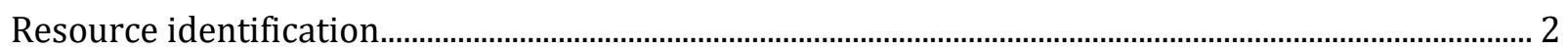

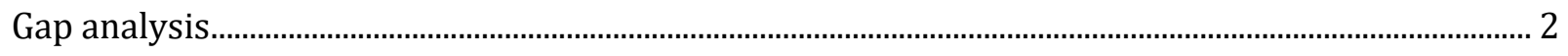

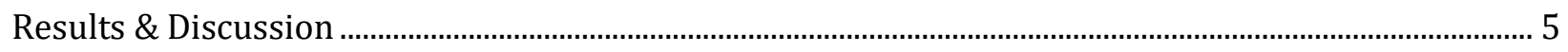

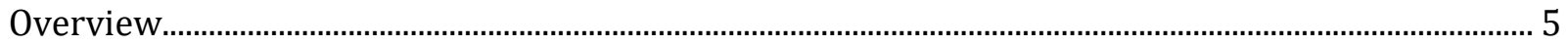

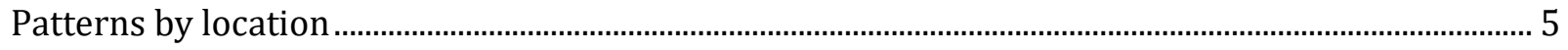

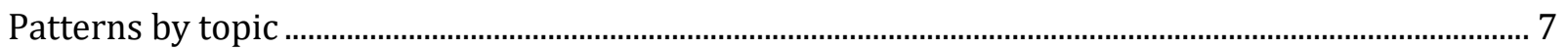

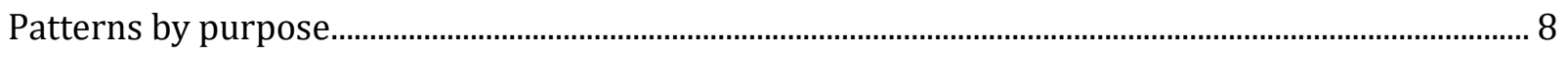

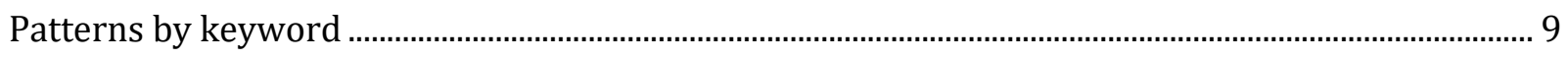

Patterns by authorship ...................................................................................................................... 10

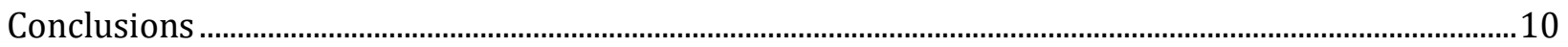




\section{Executive Summary}

A key challenge to the forests in the northeastern United States (US) is fragmentation - the breaking up of contiguous forest cover - and the resulting reduction of important forest ecosystem processes and services. Fragmentation can affect many different aspects of a forested ecosystem, from wildlife to soils, to species composition and non-native invasions. It is also closely tied with the region's socioeconomic issues. While forest fragmentation is a pressing issue, the information, data, and materials needed to advocate for solutions can itself be fragmented.

In 2017, the Forest Ecosystem Monitoring Cooperative (FEMC) governance committees recognized this gap in information availability and knowledge transfer. Many stakeholders acknowledged difficulty in locating pertinent resources for decision-making, planning, and education. We identified a number of important efforts underway to address these needs, like the Staying Connected Initiative (http://stayingconnectedinitiative.org/), but concluded that an information clearinghouse spanning all topics related to fragmentation was lacking.

The FEMC responded to these concerns by creating the Northeast Forest Fragmentation Information Network (FragNet), a novel information clearinghouse containing hundreds of resources related to forest fragmentation and parcelization in the northeastern US. FragNet aims to provide improved access to information and resources needed to understand and address forest fragmentation and parcelization. Users of FragNet can easily select resources by type, topic, or purpose, as well as by keyword, location, time period, or a combination of these criteria. FragNet can be accessed via https://www.uvm.edu/femc/fragnet. Here we provide background on the development of FragNet, as well as analysis of the resources housed on FragNet at the time of launch. The goal of this analysis was to evaluate patterns in resources by topic, purpose, location, and time, as well as identify gaps that could lead to avenues for additional work.
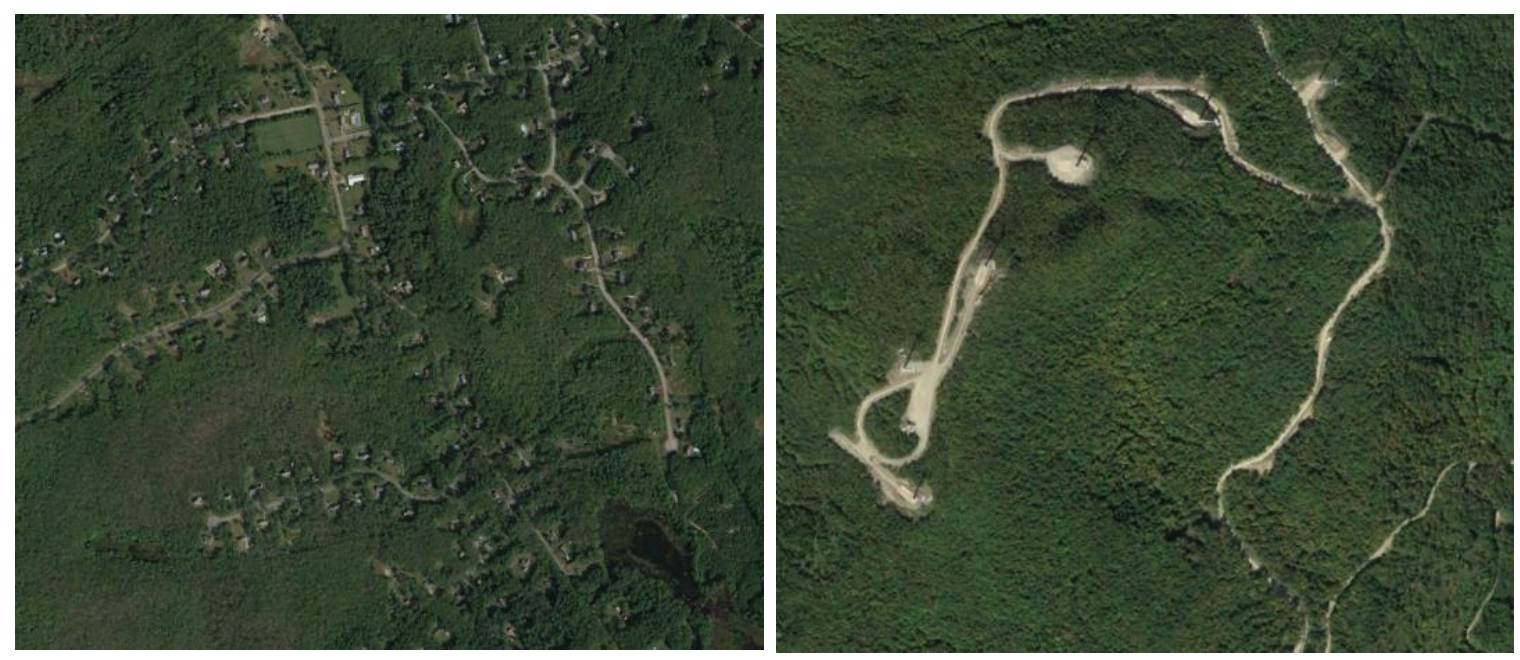

Figure 1. Examples of forest fragmentation in the Northeast from Google Digital Globe imagery. 


\section{Methodology}

\section{Resource identification}

Resources selected for inclusion on FragNet were discovered via internet search engine queries. The Northeast region was defined as the seven states in the northeastern most part of the US: Connecticut, Massachusetts, Maine, New Hampshire, New York, Rhode Island, and Vermont. We used both Google and Google Scholar for locating resources. We used a grouping of one topic keyword and one location keyword to locate resources online, using combinations of the follow keywords:

- $\quad$ Topic keyword: forest fragmentation, fragmentation, forest parcelization, parcelization

- Location keyword: Connecticut, Massachusetts, Maine, New Hampshire, New York, Rhode Island, Vermont, New England, Northeast, Northeastern

For each search, at a minimum we examined the first four pages of search engine results for suitable resources. We considered a range of resource types, from websites to scientific journal articles, as listed in Table 1.

To add a resource to FragNet, we gathered or generated the information necessary to populate the fields listed in Table 1. For some of these variables, we generated a list of options. For example, the type of resource can only be selected from the list of options in the right column of Table 1. FEMC staff assigned a type to each resource, as well as determined associated topics (one or more topics allowed from predetermined list; see Table 1), purpose (one of more purposes allowed from predetermined list: see Table 1), and keyword tags. We also determine the smallest spatial extent of the resource for geographic searching, noting that locations in FragNet are nested. For example, if a research study occurred in a county, that resource is also discoverable in a query for the state in which that county resides.

\section{Gap analysis}

We inventoried and assessed all resources housed on FragNet as of January 15, 2019. We examined patterns of resources housed in FragNet based on aggregation by the variables listed in Table 2 . We analyzed the number of resources per criterion or by multiple criteria to identify where there may be gaps in resources available on FragNet. 


\begin{tabular}{|c|c|c|}
\hline Field & Description & Options \\
\hline Title & The title of the resource provided by the author(s). & \\
\hline Key personnel & A list of the resources' authors, if available. & \\
\hline Key institutions & $\begin{array}{l}\text { A list of the institutions associated with this resource, if } \\
\text { available. }\end{array}$ & \\
\hline Start date & $\begin{array}{l}\text { The first date available for the resource, e.g., earliest data } \\
\text { used or start of project. }\end{array}$ & \\
\hline End date & The end date or publication date of the resource. & \\
\hline Location & $\begin{array}{l}\text { The spatial extent of the work or organization. Note that } \\
\text { locations are hierarchical. }\end{array}$ & $\begin{array}{l}\text { State }(s) \text {, county/counties, } \\
\text { or town(s) }\end{array}$ \\
\hline Citation & $\begin{array}{l}\text { An APA formatted citation for the resource generated by } \\
\text { Google Scholar, embedded in the resource, or, if not } \\
\text { available, created by FEMC staff using accessible } \\
\text { information. }\end{array}$ & \\
\hline Summary & $\begin{array}{l}\text { A short overview of the resource, which may be modified } \\
\text { from the abstract or executive summary or created by } \\
\text { FEMC staff. }\end{array}$ & \\
\hline Resource type & $\begin{array}{l}\text { The type of resource, selecting one option from the } \\
\text { predetermined list. }\end{array}$ & $\begin{array}{l}\text { Article } \\
\text { Book } \\
\text { Dataset } \\
\text { Digital media } \\
\text { Map } \\
\text { Policy } \\
\text { Report } \\
\text { Website }\end{array}$ \\
\hline Keyword tags & $\begin{array}{l}\text { Key word(s) to allow resource to be discoverable with } \\
\text { search terms. }\end{array}$ & \\
\hline Topic tags & $\begin{array}{l}\text { The topics addressed by the resource, selecting one or } \\
\text { more options from the predetermined list. }\end{array}$ & $\begin{array}{l}\text { Conservation } \\
\text { Ecosystem services } \\
\text { Drivers } \\
\text { Landscape pattern and } \\
\text { connectivity } \\
\text { Management } \\
\text { Methods } \\
\text { Planning } \\
\text { Wildlife and habitat }\end{array}$ \\
\hline Purpose tags & $\begin{array}{l}\text { The primary use(s) of the resource, selecting one or } \\
\text { more options from the predetermined list. }\end{array}$ & $\begin{array}{l}\text { Conservation } \\
\text { Education } \\
\text { Management } \\
\text { Policy }\end{array}$ \\
\hline Source link & $\begin{array}{l}\text { The source location of the resource on the internet, if } \\
\text { available. }\end{array}$ & \\
\hline
\end{tabular}


Table 2: List of variables used to analyze patterns and gaps in FragNet resources.

\begin{tabular}{|c|c|c|}
\hline Variable & Description & Options \\
\hline Spatial scale & $\begin{array}{l}\text { Classification of the location of the resource } \\
\text { into the geographic extent it encompasses. } \\
\text { Note that region was used when the spatial } \\
\text { scale covered four or more adjacent states. }\end{array}$ & $\begin{array}{l}\text { Region ( } \geq 4 \text { states) } \\
\text { Multiple states }(<4 \text { states) } \\
\text { State } \\
\text { Region within a state } \\
\text { Multiple counties within a state } \\
\text { County } \\
\text { Multiple towns within a state } \\
\text { Town }\end{array}$ \\
\hline Location (US State) & $\begin{array}{l}\text { Classification of the resource into the state } \\
\text { or states in which it occurred. }\end{array}$ & $\begin{array}{l}\text { Connecticut } \\
\text { Massachusetts } \\
\text { Maine } \\
\text { New Hampshire } \\
\text { New York } \\
\text { Rhode Island } \\
\text { Vermont }\end{array}$ \\
\hline Year of publication & $\begin{array}{l}\text { Classification of the end date of the } \\
\text { resource into the year in which it occurred. }\end{array}$ & \\
\hline Primary organization & $\begin{array}{l}\text { Classification of the primary organization } \\
\text { responsible for the resource. }\end{array}$ & $\begin{array}{l}\text { Academic } \\
\text { Government } \\
\text { Non-profit } \\
\text { Other }\end{array}$ \\
\hline Purpose & The primary use(s) of the resource. & $\begin{array}{l}\text { Conservation } \\
\text { Education } \\
\text { Management } \\
\text { Policy }\end{array}$ \\
\hline Topic tag & $\begin{array}{l}\text { The topic } \operatorname{tag}(\mathrm{s}) \text { use to describe the } \\
\text { resource. }\end{array}$ & $\begin{array}{l}\text { Conservation } \\
\text { Ecosystem services } \\
\text { Drivers } \\
\text { Landscape pattern and } \\
\text { connectivity } \\
\text { Management } \\
\text { Methods } \\
\text { Planning } \\
\text { Wildlife and habitat }\end{array}$ \\
\hline
\end{tabular}




\section{Results \& Discussion}

\section{Overview}

The first version of FragNet launched in October 2018 and contained nearly 300 resources on fragmentation and parcelization in the northeastern US. Resources housed on FragNet can be easily browsed by type, topic, or purpose, as well as filtered by keyword, date range, or location. Every six months, FEMC staff will search for newly added or published resources online using the established keyword search outlined in the methodology; here we provide analysis of the resources on FragNet as of January 2019. Note that this analysis only includes resources that were discoverable on the internet following our described methodology and were included on FragNet. We present these patterns by spatial location, timeframe, topic, purpose, and authorship.

\section{Patterns by location}

By spatial extent, $47 \%$ of FragNet resources encompassed a single state (Figure 2). While this is logical given that funding for resources may come from a state agency, fragmentation drivers and effects are generally similar across states in the Northeast and the ecological processes that may be impacted by fragmentation are not confined to geopolitical boundaries. Policies, are an exception, as they often must be implemented at the state level due to political systems. We did find that the

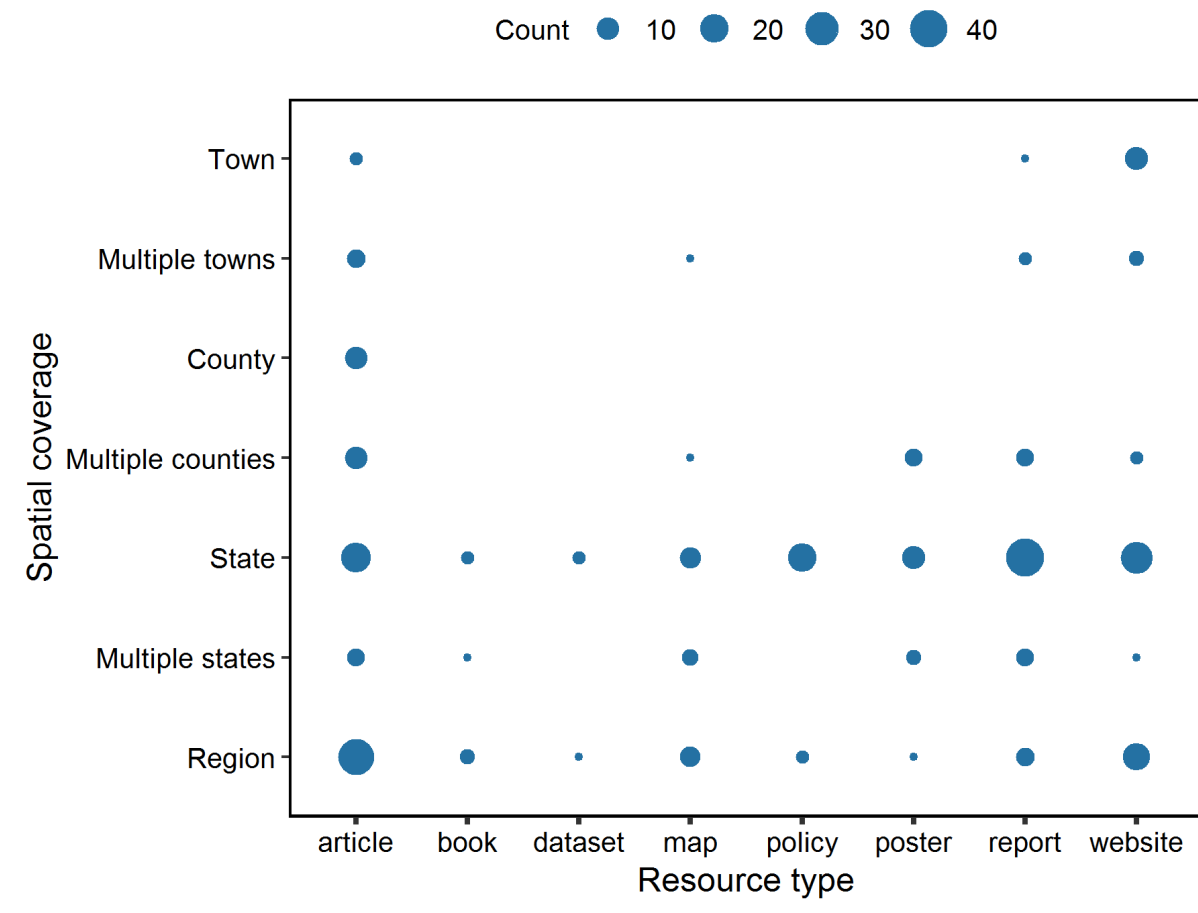

Figure 2: Count of FragNet resources by spatial extent and type. A resource can only be only classified as a single type and spatial coverage. Note that region is defined as four or more adjacent states. 
majority of policies occurred at the single state level, although there were a small number that addressed fragmentation at a larger scale. Most technical reports on fragmentation were also represented at the state level.

Both state and regional scales were represented by all types of media we included on FragNet. Over time we see that resources spanning a state or a region (here region was defined as $\geq 4$ states) increased drastically, while resources at the other scales remained level (Figure 3). About $25 \%$ of FragNet resources had a regional focus (Figure 2). In particular, scientific articles were predominantly regionally focused. Research articles were the only resource type that covered all spatial scales, from a single town to the larger region (Figure 2).

By state, the most resources housed on FragNet included Vermont (Figure 4). Despite size and forest cover differences, the other six states were represented by a comparable number of total resources. The large number of resources from Vermont was driven by a greater number of various media types, in particular more maps, reports, websites, and policies, compared to the other

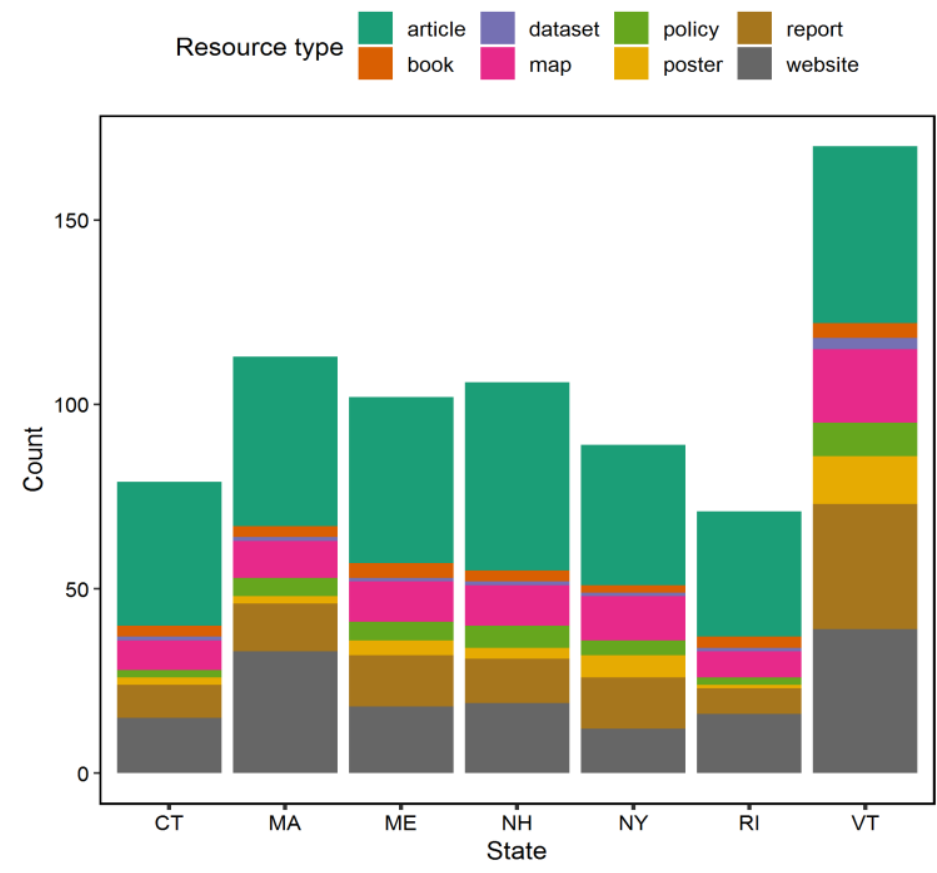

Figure 4: Distribution of resources by state and type. Note that a resource can encompass more than one state, but can only be classified as one type.
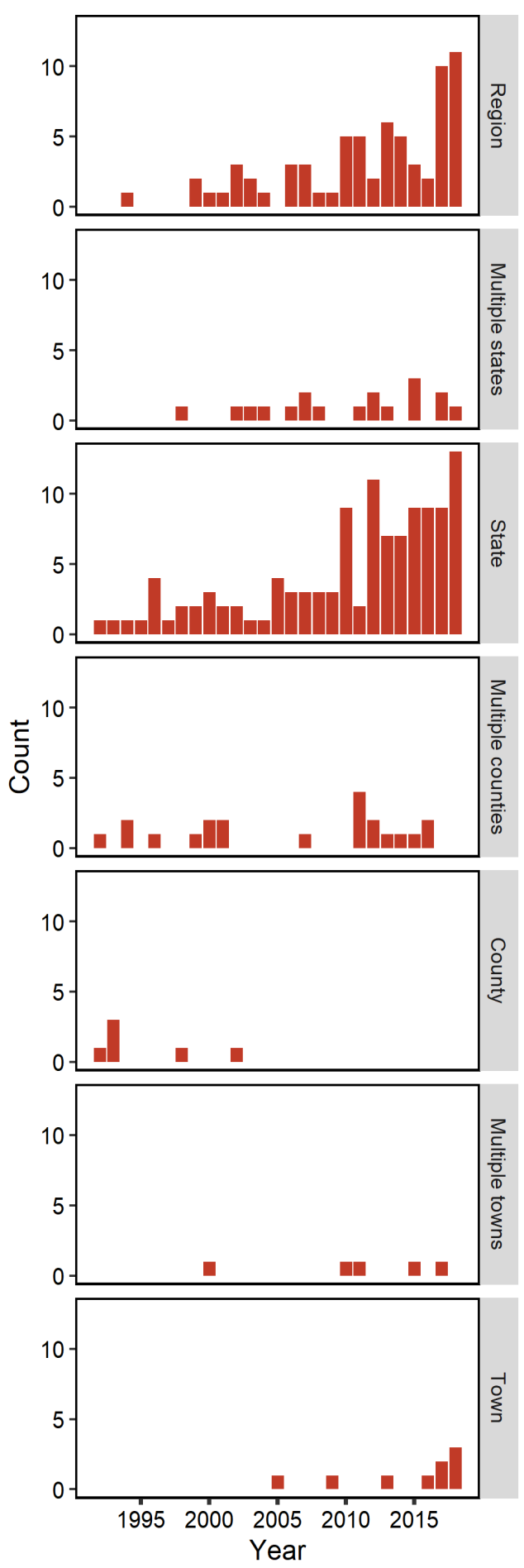

Figure 3: Count of FragNet resources by year of publication and spatial coverage. For clarity, only the years 1990-present are depicted. 
states in the region. We saw no discernable patterns when we examined the topic of the resource and the state or spatial scale it encompassed, which indicates that there is good topical representation in resources across the region.

\section{Patterns by topic}

The number of resources discoverable via web searches increased considerably over time (Figure 5Error! Reference source not found.) - which is to be expected considering that older resources may not be in a digital format and information on the web is continuously expanding. However, it also suggests that interest in and/or concern about forest fragmentation has increased. In particular, there has been a rise in the number of resources with topics related to conservation, ecosystem services, and landscape pattern and connectivity, indicating perhaps, a refocus on the spatial and ecological impacts of forest fragmentation, which is supported by Figure 3.

It is interesting to note that resources with a management topic have declined in the most recent decade. This is an important finding considering that managers and policy makers often require concrete suggestions based on scientific data in order to effectively plan and manage for fragmentation. This decline in management-focused resources could be due to a number of reasons, including lack of funding, reprioritization of efforts, view of fragmentation as a policy issue rather than management, or insufficient data on some other aspect of fragmentation needed to inform management. Regardless, the FEMC staff commonly hears that managers are seeking concrete, well-informed steps that
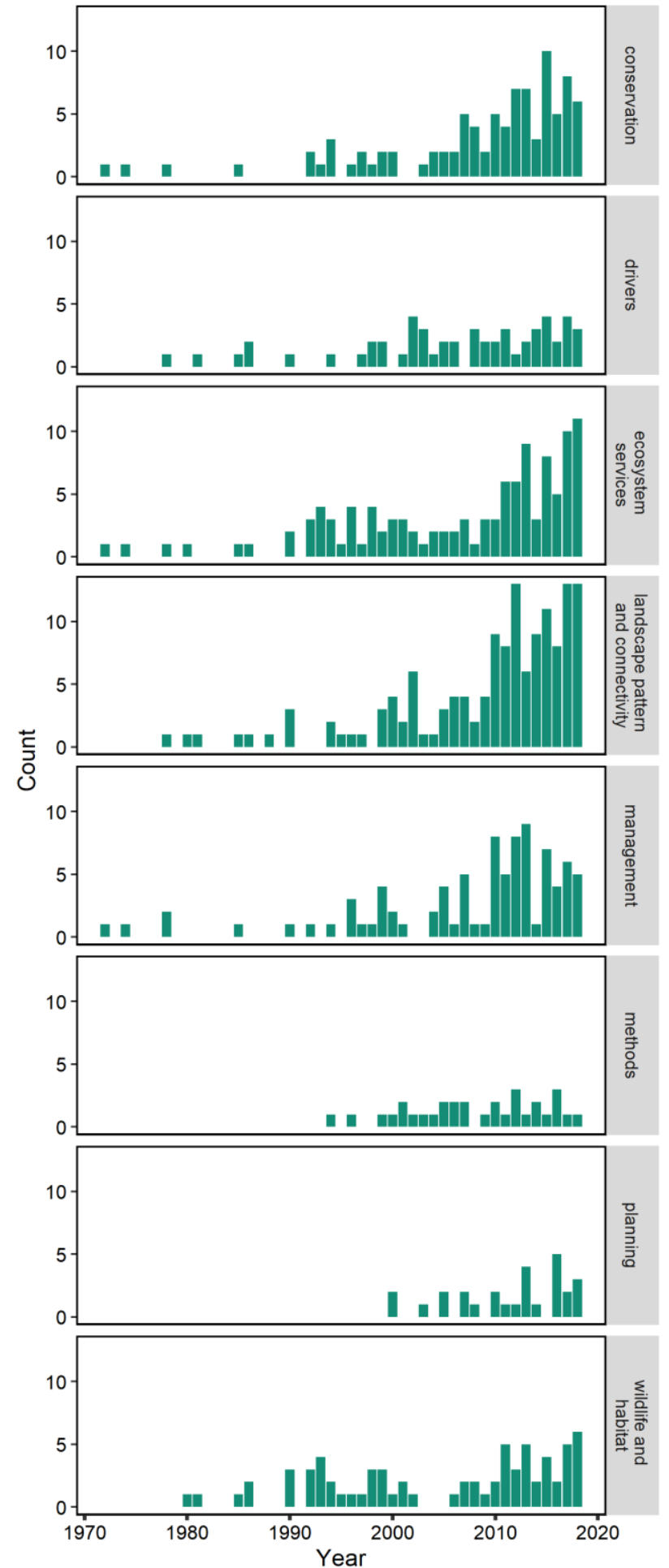

Figure 5: Count of Frag Net resources by topic tag by the year of publication or release. Note that a resource can have more than one topic tag. 
they can follow to achieve a certain goal. Providing more management-focused resources could be an important area of growth.

As management-focused resources declined, both landscape pattern and connectivity and ecosystem services focused resources have increased in recent years. Both of these topics may allow for justification of policies aimed at mitigating or minimizing fragmentation and provide an economic incentive to preserve forests. It also supports the finding that more resources are being produced with a larger spatial extent (state, region).

When we compared resource types with the topics of the resource, we see some interesting patterns (Figure 6). Policies are mostly directed towards management, ecosystem services, and conservation. Websites are predominately geared for conservation, although websites do cover the full suite of topics. Interestingly, wildlife and habitat was a predominant topic in the scientific articles housed on FragNet, but this topic is not well represented across the other types of sources, aside from websites.



The majority (42\%) of resources on FragNet were deemed to have an educational purpose. This can vary from research studies that aim to progress the understanding of the links between fragmentation and water quality to a website that outlines the impacts of fragmentation on wildlife. Conservation and management purpose resources were represented at similar amounts (about a 
quarter of all resources for both), with policy only identified for less than $8 \%$ of resources. Note that resources can have multiple purposes, though most only have one or two.

Over time we see that the number of educational resources has increased considerably, while the other purposes remain steady or are declining in frequency (Figure 7). The slow decline in the number of resources with a management purpose aligns with the concurrent decline in management as a resource topic, as depicted in Figure 5. We expected to see an increase in resources with a policy purpose as time progressed, but this was not evident (Figure 7).

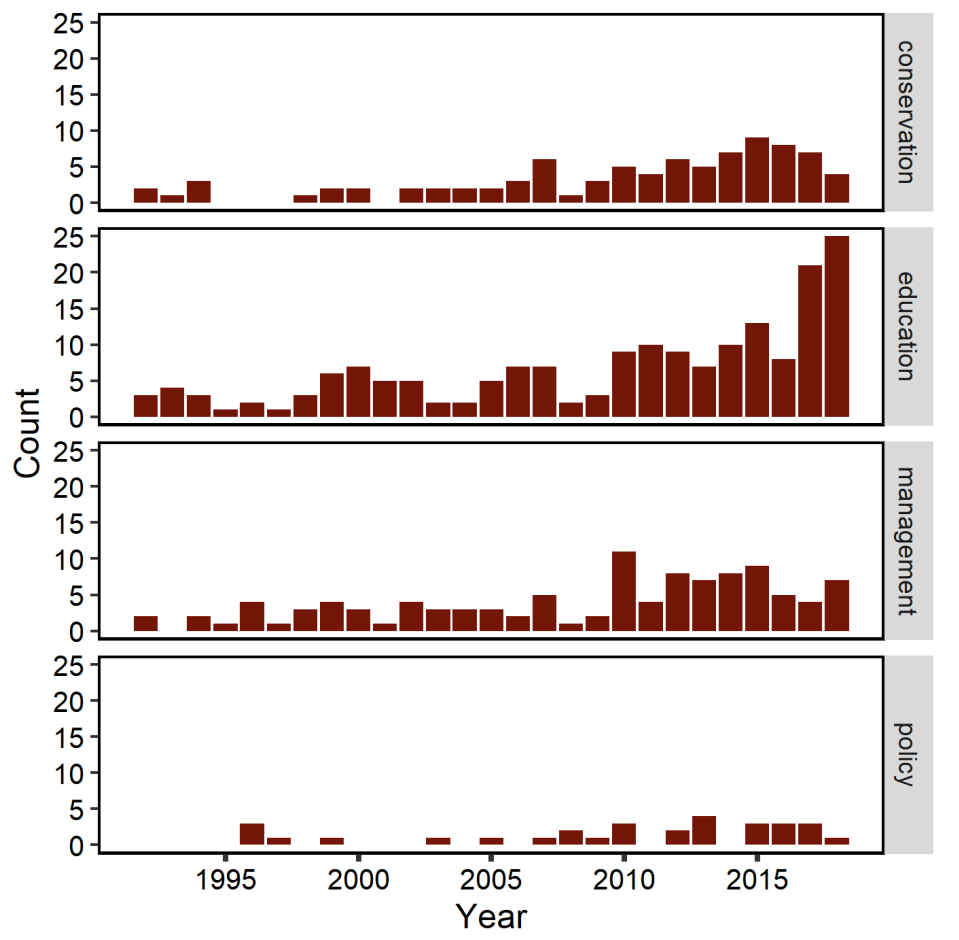

Figure 7: Count of Frag Net resources by the purpose of the resource over time. For clarity only resources with a release date $>1990$ are shown. Note that 2019 is only a partial year of data.

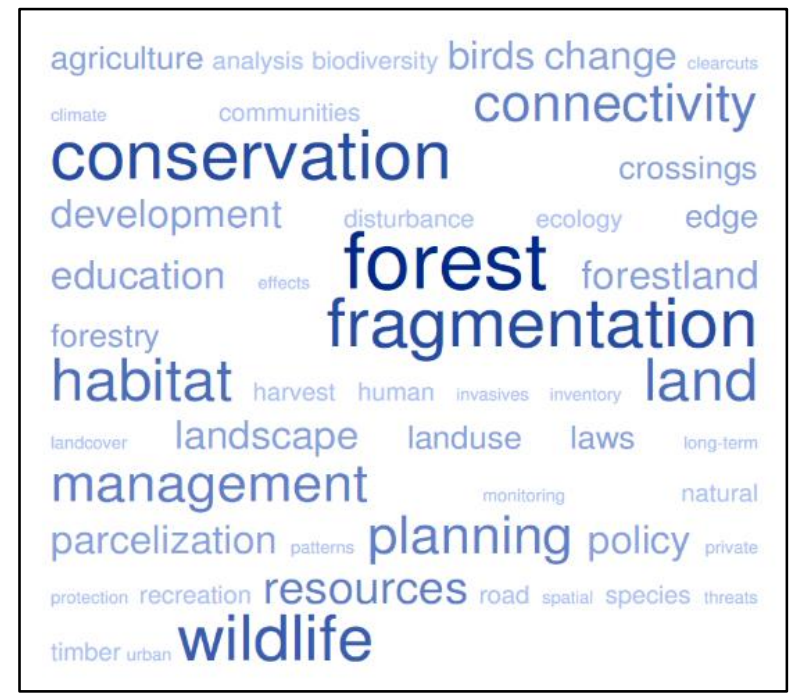

Figure 8: Visualization of resource keyword tags where the size of the font depicts the frequency.

\section{Patterns by keyword}

There were over 500 unique tags used to describe the resources on FragNet. Figure 8 illustrates the most common keywords associated with resources housed on FragNet. Note that these keywords were not selected from a predetermined list, but were used to uniquely describe a resource for improved searching. Not surprisingly, forest and fragmentation were two of the most common keywords, along with conservation, wildlife, habitat, planning, and connectivity. Most keywords related to landscape patterns and biota. Of the highly used words, there were few that were implicitly associated with socioeconomic factors, which may drive, and be impacted by, forest fragmentation. 


\section{Patterns by authorship}

Looking at the organization that authored or released each of the FragNet resources, we see that academic intuitions (e.g., universities, colleges) are associated primarily with scientific journal articles (Figure 9). Government organizations, on the other hand, produce articles, maps, policies, and reports in nearly equal amounts. Non-profits dominated fragmentation websites, but also produced a large number of reports along with other media. We failed to see any discernable patterns by the organization type and the topic of the resource; there were fairly equal distributions of the topics across organizations. The one exception, was that there was a slightly higher number of management-focused resources from government agencies.

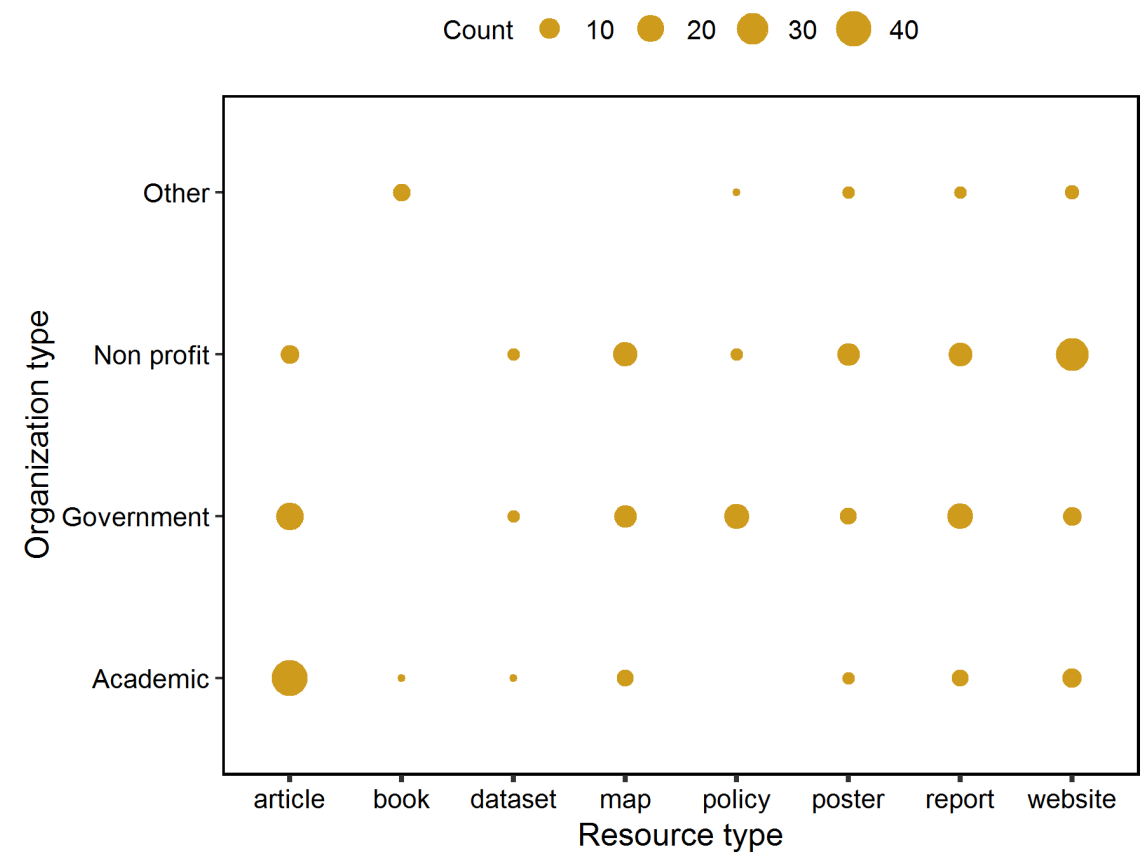

Figure 9: FragNet resource type by organization type that

produced the resource. Size of points represent the count. Note that a resource can only be of one type, but could be associated with more than one type of organization.

\section{Conclusions}

FragNet, the Northeast Forest Fragmentation Information Network (https://www.uvm.edu/femc/fragnet), is the first attempt to collate and curate a comprehensive collection of resources on forest fragmentation and parcelization for the northeastern US. There are other notable groups in the region that have collated resources on a specific topical focus, like the Staying Connected Initiative (http://stayingconnectedinitiative.org/). FragNet includes many resources by Staying Connected, and spans topics outside of wildlife habitat concerns. Thus, 
FragNet can act as a centralized location to search and discover information related to fragmentation and parcelization.

The FEMC created FragNet to make it easier to find resources that match a specific need by being able to browse by the topic, purpose, location of a resource, or search by various keywords. As new resources are developed and released, the FEMC will continually update FragNet to house the latest sources of information.

As forest fragmentation garners more interest and concern region wide, we hope that this analysis of the patterns in current resources will help identify gaps that could be filled. For example, increasing management focused resources or including socioeconomic factors in understanding causes and consequences of forest fragmentation would enrich and expand the current wealth of knowledge on the subject. 

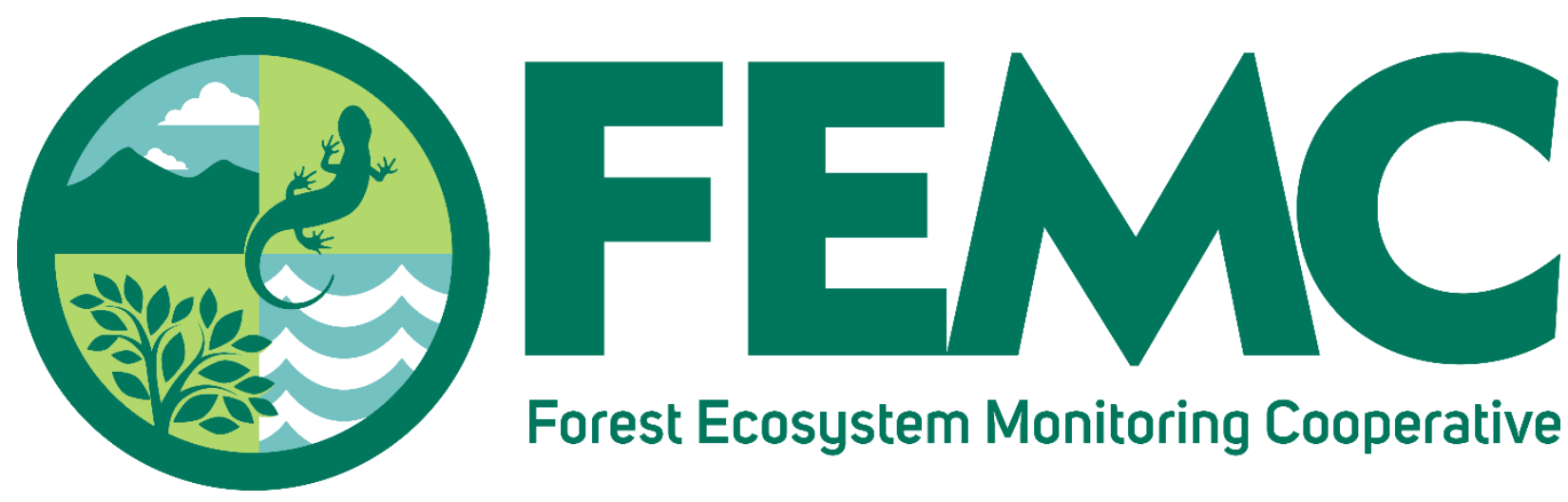

\section{Forest Ecosystem Monitoring Cooperative}
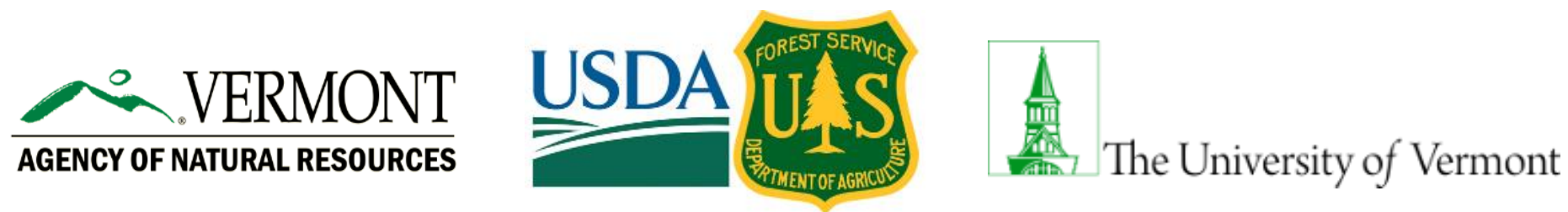

The U.S. Department of Agriculture (USDA) prohibits discrimination in all its programs and activities on the basis of race, color, national origin, age, disability, and where applicable, sex, marital status, familial status, parental status, religion, sexual orientation, genetic information, political beliefs, reprisal, or because all or part of an individual's income is derived from any public assistance program. (Not all prohibited bases apply to all programs.) Persons with disabilities who require alternative means for communication of program information (Braille, large print, audiotape, etc.) should contact USDA's TARGET Center at 202-720-2600 (voice and TDD). To file a complaint of discrimination, write to USDA, Director, Office of Civil Rights, 1400 Independence Avenue, S.W., Washington, D.C. 20250-9410, or call 800-795-3272 (voice) or 202-720-6382 (TDD). USDA is an equal opportunity provider and employer.

Providing the information needed to understand, manage, and protect the region's forested ecosystems in a changing global environment 